Article

\title{
The Influence of Knowledge and Education in Public Risk Perception. A Case Study in Calabria (Southern Italy)
}

\author{
Roberto Coscarelli $^{1 *}$, Loredana Antronico1, Francesco De Pascale ${ }^{2}$, Francesca Condino ${ }^{3}$ \\ 1 Research Institute for Geo-hydrological Protection (CNR-IRPI), National Research Council of Italy, Rende, \\ CS, Italy; r.coscarelli@irpi.cnr.it; 1.antronico@irpi.cnr.it \\ 2 Department of Languages and Educational Sciences, University of Calabria, Rende, Cosenza, Italy; \\ fr.depascale@gmail.com \\ 3 Department of Economics, Statistics, and Finance, University of Calabria, Rende, Cosenza, Italy; \\ francesca.condino@unical.it \\ * Correspondence: r.coscarelli@irpi.cnr.it ; Tel.: +39-0984-841417
}

\begin{abstract}
Climate change is increasing the occurrence of disastrous events in the world, but several disparities in population vulnerability are being registered. One of the causes of these variances is different public risk perception also due to the degree of education and knowledge of the population. In this study, some of the results obtained in a risk perception survey are presented. The survey was carried out in an area of Calabria (Southern Italy) hit by geo-hydrological events that have occurred in recent years with damage to roads, tourism facilities and private houses. A statistical interpretation of the results highlights the importance of education and knowledge to risk perception on the part of the population investigated.
\end{abstract}

Keywords: risk perception; geo-hydrological risk; education; Southern Italy

\section{Introduction}

Climate change, with its strong impact on events such as floods, landslides, droughts [e.g., 1-5], are determining an increase of natural disasters that are frequently occurring all over the world and affecting people's lives and livelihoods. In other way, several disparities regarding population vulnerability seem to exist among nations and among communities within the same country [6]. Governance, health, and education are considered the three main determinants, at the national level, of vulnerability [7]. Toya and Skidmore [8] evidenced that both higher income and educational level are important measures of development in reducing vulnerability to natural disasters. The education level as a predictor of the vulnerability to floods and landslides was tested in Nepal [6] through two sources of data: the yearly data on losses caused by flood and landslides, at the village level, and microdata at the individual level. The comparison of these two typologies of data allowed establishing that the educational level of a community is associated with its vulnerability to floods and landslides. Shewmake [9] proved that "years of schooling" is a highly significant variable to explain the variation in vulnerability of South African farmers to climate change. In fact, it is known that societies with a higher education level are more adaptive in the response to disasters and have greater capabilities for adaptation to climatic change [10]. Wamsler et al. [11] proved that individuals with a higher level of education have better ability to perceive and understand existing risks and, in this way, to reduce vulnerability in terms of life losses, injury, morbidity and damage. Garbero and Muttarak [12], analysing the impacts of floods and droughts on the Thailand communities, showed that highly educated individuals or households have greater flexibility and skills to take up a new job to cover the income loss caused by climatic stresses. Education has an important role in reducing the negative impacts of extreme climate events both in a direct and an indirect way. Directly, formal education is the first way with which everyone can acquire knowledge and competencies, thus improving his adaptive capacity. It was proved [13-15] that in an emergency situation, educated 
individuals are more able to respond to the event. Moreover, education enhances knowledge on disaster risks and influences risk perception. If people perceive natural disaster risks as real, they are more likely to cope with them [16-17]. There are also indirect impacts of the education level on a decreased vulnerability. Several Authors [18-20] evidenced that highly educated individuals usually have various communication ways and have better access to useful information: this implies a better access to important information, such as early warnings for extreme storms or seasonal droughts [2123]. Also the social networks can have in important role in emergency. Mileti and Sorensen [24] evidenced that individuals who are in large social networks or friendship groups have more chances to receive informal warnings and consequently to respond in a better way.

In this paper, starting from a survey on risk perception in an area of Southern Italy [25] that in recent years has been affected by shallow landslides and debris flows with damage to infrastructures and properties, some of the outcomes are analyzed to put in evidence the importance of education and knowledge in risk perception, and thus in the public vulnerability.

\section{Materials and Methods}

\subsection{The study area}

The study area is located along the Tyrrhenian coast of Calabria (Southern Italy). The risk condition of the study area is due to its morphological and geological characteristics [26]. Narrow and deep canyons, linked to fault systems that cross the outcropping rocks, dissect the steep slopes. The narrow coastal plain, at the mouths of the canyons, is affected by a set of alluvial fans consisting of debris-flow deposits, linked to past landsliding activity phases. Antronico et al. [26], based on documentation about historical debris flow and flood events, found that these alluvial fans were inactive from 1955 to 2008. Also owing to the absence of hazardous geo-hydrological events, in the last few decades an intense urbanization has characterized this area. In particular, this intensive urban growth has consisted mainly of several tourist facilities because this stretch of Southern Italy is famous for its natural beauty. In the period 2009-2011 several rainfall events hit the study area producing many shallow landslides and debris flows, in particular in the months January 2009, October 2010, March 2011. Damage was mainly registered (Figure 1) in the three municipalities of Tropea, Parghelia and Zambrone [26].

\subsection{Methods}

To analyse the risk perception by the population of the above-mentioned municipalities and also to evaluate their preparedness level to overcome a disaster event, Antronico et al. [25] proposed a structured questionnaire consisting of 58 queries with close responses (yes/no, multiple-choice, fivepoint scale) or open-ended answers. In particular, the queries included socio-demographic questions (age, gender, educational level, occupation, etc.), the level of knowledge of the geo-hydrological phenomena, the involvement in past geo-hydrological events, the perception of the exposure to geohydrological risk, the information on the geo-hydrological risk, the role of communication, and the feeling of safety. The total population of the three selected municipalities is about 10,000 inhabitants (2011 Italian Census), living on a total area of about $28 \mathrm{~km}^{2}$; the questionnaire was submitted face-toface to 300 people, choosing a non-proportional quota sampling. Some of the results obtained were shown in [25]. In this paper, the importance of knowledge and the influence of the education level in public perception of the exposure to geo-hydrological events have been analysed, evaluating the correlation between the answers to some peculiar queries strictly linked to these aims. For this reason, the categorical variables were expressed as counts and percentages, and continuous variables were shown by mean and standard deviation. To evaluate the possible dependence between two categorical variables of interest, the two-way contingency table and the associated Person chi-square test (or Fisher exact test, when the expected frequencies were low) were considered. In order to measure the strength and direction of association existing between two variables measured on at least 
an ordinal scale, the non-parametric Kendall's tau-b correlation coefficient was considered. In all the statistical tests the significance level was set at $5 \%$.

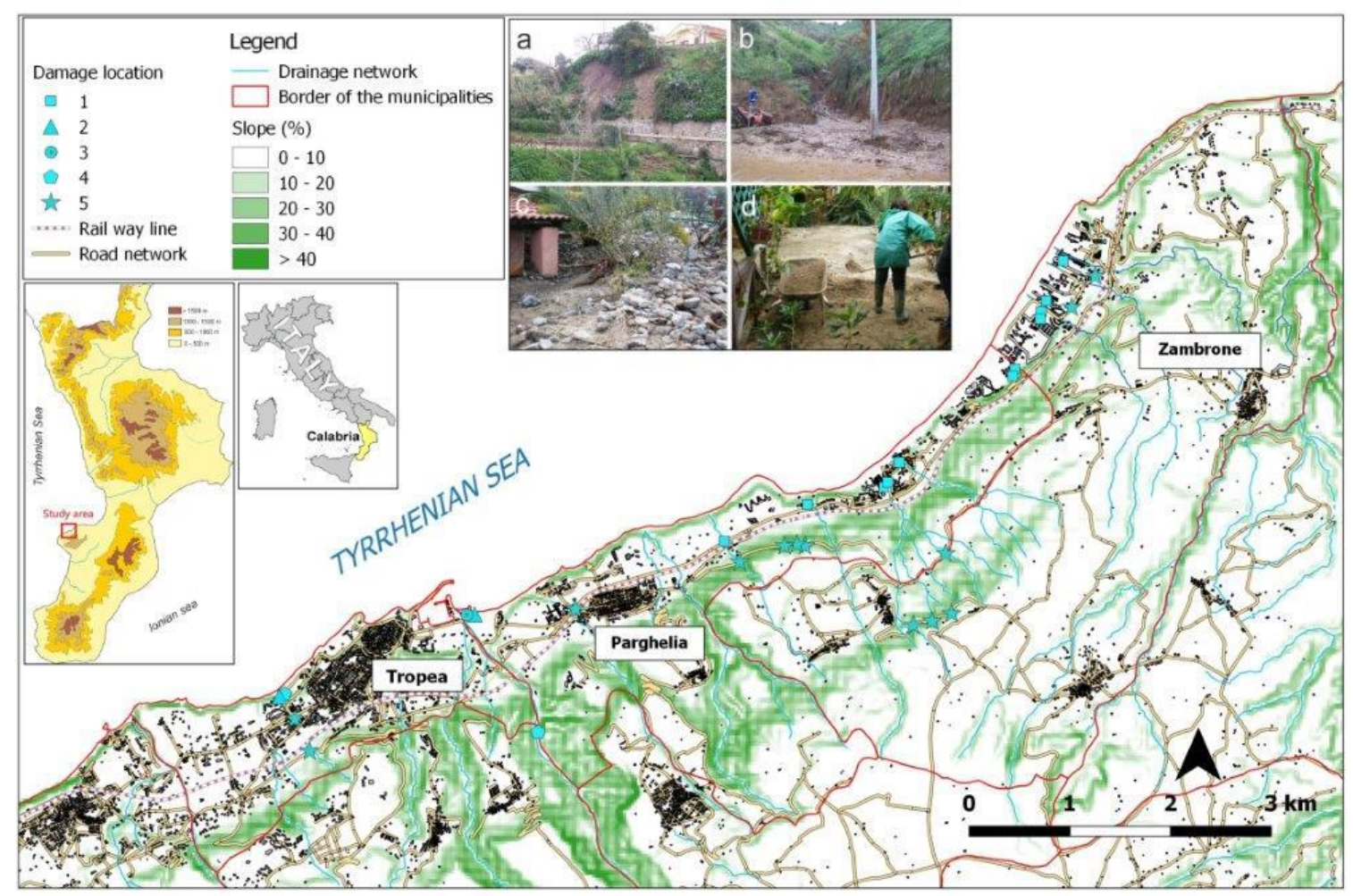

Figure 1. Study area with indication of damage during the 2009-2011 geo-hydrological events. Legend: 1) damage to hotel and resort; 2) damage to beach facilities; 3) damage to tourist harbor; 4) damage to wastewater treatment plant; 5) blocked roads and/or roads covered by debris (from [26] modified). Some photos of the damage are shown: a) shallow landslides triggered during the 2010 event near Tropea; b) a provincial road in the Municipality of Tropea affected by a debris flow during the 2009 event; c), d) debris flow damage caused by the 2009 event to a hotel in the Municipality of Parghelia.

\section{Results}

The respondents' age ranges from 18 to 89 with a homogenous distribution: $31 \%$ with an age between 18 and 39 years, $36 \%$ of the persons $40-59$ years, and 33\% are more than 60 years old. Regarding the education, Figure 2 shows the distribution of the levels: the major part (48\%) has a secondary education level and about one quarter has a degree. Only $1 \%$ of the respondents are without an educational title.

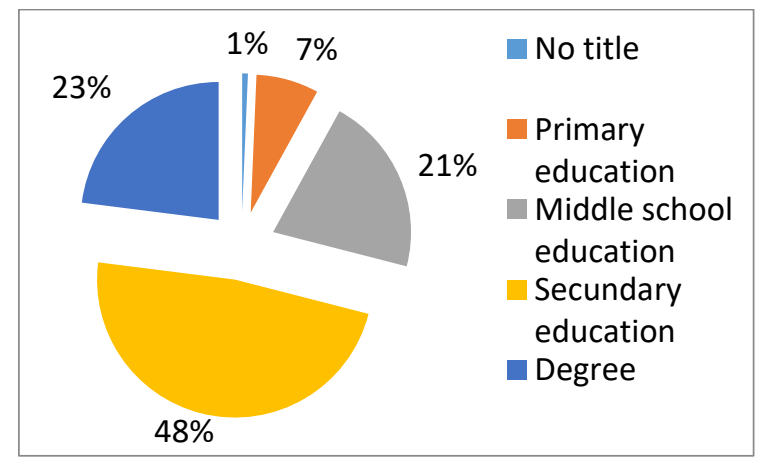

Figure 2. Distribution of the education level of the respondents. 
Regarding the actual occupation, about $54 \%$ have a stable occupation (employed, manager, entrepreneur, artisan, farmer, etc.), $18 \%$ are retired, $12 \%$ unemployed, $6 \%$ students, $6 \%$ housewives, and $4 \%$ answered "other".

One of the most important queries about the public risk perception was "How much do you think you are exposed to the selected events?". Figure 3 shows the results, distinguishing the exposure to natural (floods, earthquake, etc.) and anthropic events (car accident, terroristic attacks, etc.). The results clearly show that the highest feelings about the exposure to events regard earthquake (about of the $77 \%$ of the persons), flood (70\%) and landslides (66\%). On the contrary, only $3 \%$ of the sample feel high the perception of the exposure to terroristic attack. It is important to underline that the survey was carried out a few months after the strong earthquake of Central Italy, whose dramatic images sentimentally touched all the Italian population.

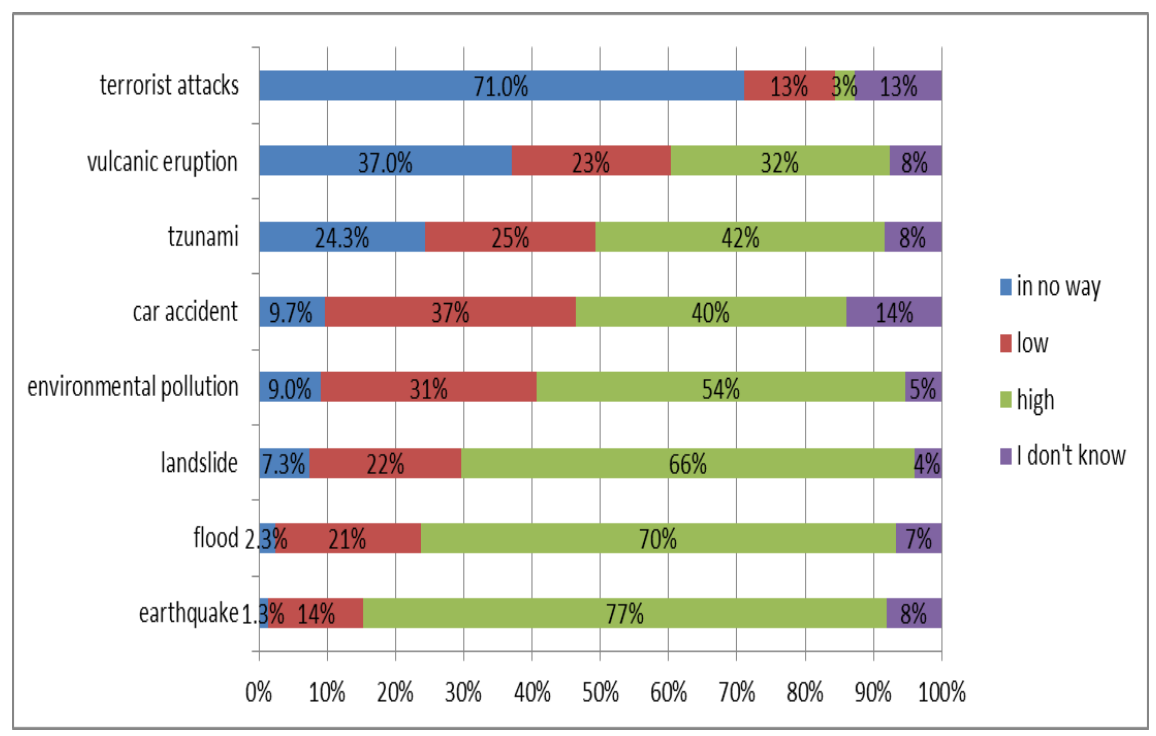

Figure 3. Results regarding the query "How much do you think you are exposed to the selected events?" [25].

In particular, referring to other queries relative to only floods and landslides, $45 \%$ of the persons estimate high the probability that one of the mentioned events could occur in the place where they live or work. Moreover, for $54 \%$ of the persons the probability that these events can cause damage to people and/or property is high.

In relation to the causes of flood or landslides, a multiple-choice query furnished the following results: 222 out of 300 think that these events are caused by man and a lower numbers of respondents think that they are "natural events" (119) and "unforeseeable events" (76). Only 9 persons think that flood or landslides are "caused by a divine punishment": almost all of them are over 60 and all retired.

Regarding the historical memory of the population, $68 \%$ of the respondents remember that in the past flood and landslides occurred in the places where they live or work; only $7 \%$ do not remember historical events, including the events of the years 2009-2010. These outcomes are resulted positively correlated with the perception of exposition to floods/landslides (significant only for flood).

About the personal information on weather forecasting, $44 \%$ of the respondents is frequently updated on future weather conditions and on possible alert situations. Persons mainly use "weatherweb sites" (190) and "TV" (189). On the contrary, referring to the queries about the local Civil Protection Plans (CPPs), that in Italy each municipality must adopt for citizens' protection, about 78\% of respondents know what is a CPP and what are its contents, but $62 \%$ of these do not know whether their Municipality has adopted a CPP and its specific contents. Moreover, $16 \%$ know that a CPP has 
been adopted even if its contents are unknown and, finally, only about $6 \%$ know both the existence and the contents of the CPP adopted by the Municipality where they live or work (Figure 4).

With the multiple-choice query regarding the way by which the Authorities could better protect the citizens from floods and landslides, 203 have answered "through CPPs and early warning system", 198 have chosen "protection works on the territory" and 159 preferred "information and education actions of population".

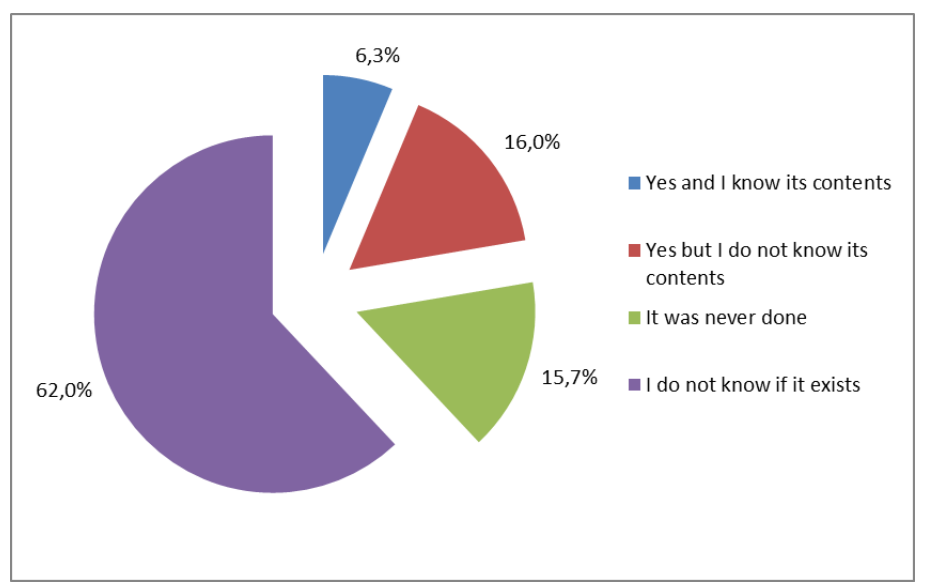

Figure 4. Results of the query about the knowledge of the Civil Protection Plan and of its contents.

Based on these results, the correlation between the respondents' age and the answers regarding the events (earthquake, flood, landslide) for which the highest exposition level was felt by the population (Figure 3) was analyzed. It results that for all three events, public perception is negatively correlated (significant only for landslide) with the age: the higher is the age of the respondent, the lower is the risk perception. Figure 5 shows the results regarding landslides.

Moreover, it results that public perception of exposition to landslides, floods, earthquakes is positively correlated with the instruction level of the respondents, even if significant only for earthquakes and landslides. Figure 6 shows the results obtained for landslides.

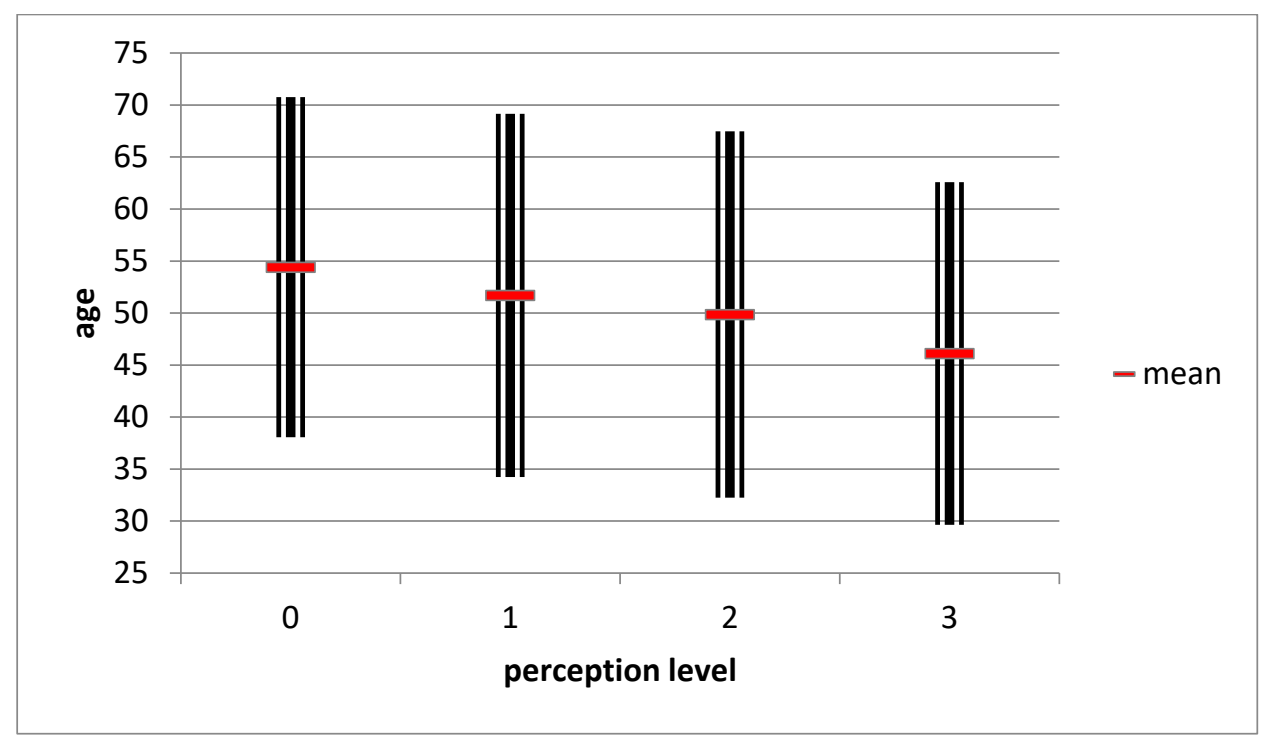

Figure 5. Box-plots (with indication of mean and standard deviation values) regarding the respondents' age for each perception level of exposition to landslides (from 0 - null to 3 - high). 


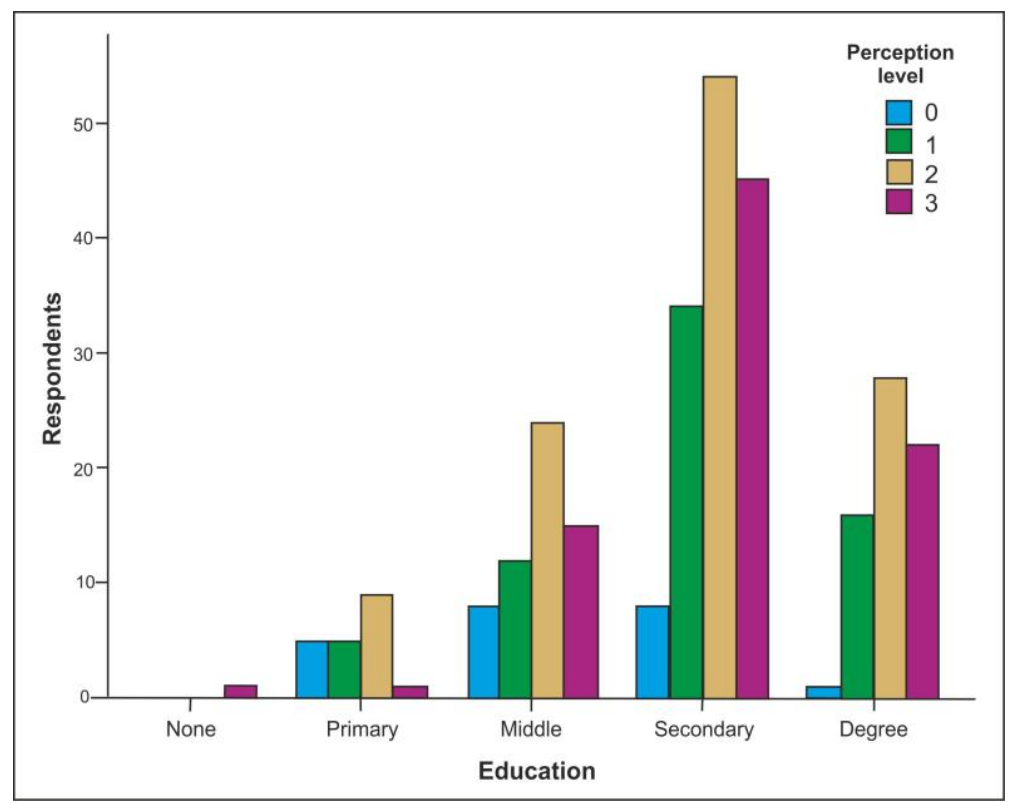

Figure 6. Results of the comparison between education and perception level of exposition to landslides (from 0 - null to 3 - high).

\section{Discussion and Conclusions}

The results obtained clearly evidence the weight of the education level in the perception of exposition to natural events, especially for landslides. In particular, it emerges that the secondary school has an important role in training awareness regarding the natural events. It is plausible that highly educated individuals have better learning skills and are better prepared to overcome an emergency. This represents a decisive first step in increasing the ability to cope with disastrous events by a population who, becoming older, seem to forget the risk perception, as the correlation of Figure 5 has clearly shown. It is useful to compare these data with those of another survey about seismic risk perception, carried out in some schools of Southern Italy (Pollino area in the Calabria and Basilicata regions), with also the involvement of a sample of adults [27-28]. In the mentioned studies, most pupils (about $92 \%$ ) and only $50 \%$ of the adults gave correct answers regarding the behavior to adopt in the case of a seismic event. Moreover, about $90 \%$ of students knew that it was impossible to predict when and where an earthquake would occur and, on the contrary, the adults exhibited great ignorance, especially in terms of specific terminology relating to seismic risk and about the behaviors to adopt during and after an earthquake.

In the survey, object of the present study, the population investigated showed a good basic knowledge on the events, on their possible causes and on the tools able to cope with the events (early warnings, Civil Protection Plans, etc.) but they seem not to have any interest to know in a detailed manner (Figure 4). Also in the mentioned seismic survey, 53\% of the adults did not know whether their municipal authorities had an emergency plan [27-28].

Even if further detailed analyses are needed, it is already clear that future scenarios regarding risk perception and indirectly public vulnerability also depend on the education policies that will be carried out in the near future. Given the protective effects that education can have in the various phases of a disaster event (pre-, during and post-), it is clear that investment in public education can have positive effects in reducing the vulnerability of the population and in enhancing their adaptive capacity. Disaster risk reduction policies must be integrated into formal education, national training and development programs, thanks to the commitment of governments and the adoption of an institutional basis for the transmission of experience [29]. Increasing citizens' education, through training and communication between institutions and citizens, grows the resilience of a territory, which is built precisely through greater interaction among the individual, society and the environment. Policies aiming at education and human capital formation seem to be the most efficient strategies to promote vulnerability reduction and enhance the adaptive capacity of population. 
Author Contributions: R. Coscarelli and L. Antronico analyzed the data; F. De Pascale carried out the questionnaire survey; F. Condino contributed with the statistical elaborations; R. Coscarelli wrote the paper.

Conflicts of Interest: The authors declare no conflict of interest.

\section{References}

1. Brunetti, M., Caloiero, T., Coscarelli, R., Gullà, G., Nanni, T., Simolo, C. Precipitation variability and change in the Calabria region (Italy) from a high resolution daily dataset. Int. J. Climatol. 2012, 32, 5773, DOI: 10.1002/joc.2233.

2. Sirangelo, B., Caloiero, T., Coscarelli, R., Ferrari, E. A stochastic model for the analysis of the temporal change of dry spells. Stoch. Env. Res. Risk A. 2015, 29, 143-155, DOI: 10.1007/s00477-014-0904-5.

3. Caloiero, T., Buttafuoco, G., Coscarelli, R., Ferrari, E. Spatial and temporal characterization of climate at regional scale using homogeneous monthly precipitation and air temperature data: an application in Calabria (southern Italy). Hydrol. Res. 2015, 46, 629-646, DOI: 10.2166/nh.2014.022.

4. Caloiero, T., Sirangelo, B., Coscarelli, R., Ferrari, E. An analysis of the occurrence probabilities of wet and dry periods through a stochastic monthly rainfall model. Water 2016, 8, 1-21, DOI: 10.3390/w8020039.

5. Caloiero, T., Coscarelli, R., Ferrari, E., Sirangelo, B. Trend analysis of monthly mean values and extreme indices of daily temperature in a region of southern Italy. Int. J. Climatol. 2017, 37, 284-297, DOI 10.1002/joc.5003.

6. KC, S. Community vulnerability to floods and landslides in Nepal. Ecol. Soc. 2013, 18(1), 8, DOI: 10.5751/ES-05095-180108.

7. Brooks, N., Adger, W. N., Kelly, P. M. The determinants of vulnerability and adaptive capacity at the national level and the implications for adaptation. Global Environ. Chang. Part A 2005, 15(2), 151-163, DOI: 10.1016/j.gloenvcha.2004.12.006.

8. Toya, H., Skidmore, M. Economic development and the impacts of natural disasters. Econ. Lett. 2007, 94, 20-25, DOI: 10.1016/j.econlet.2006.06.020.

9. Shewmake, S. Vulnerability and the impact of climate change in South Africa's Limpopo River Basin. Discussion Paper 00804, International Food Policy Research Institute, Washington, D.C., USA, 2008. http://www.ifpri.org/publication/vulnerability-and-impact-climate-change-south-africaslimpoporiver-basin.

10. KC, S., Lutz, W. Demographic scenarios by age, sex and education corresponding to the SSP narratives. Popul. Environ. 2014, 35(3), 243-260, DOI: 10.1007/s11111-014-0205-4.

11. Wamsler, C., Brink. E., Rantala, O. Climate change, adaptation, and formal education: The role of schooling for increasing societies' adaptive capacities in El Salvador and Brazil. Ecol. Soc. 2012, 17(2), 2, DOI: 10.5751/es-04645-170202.

12. Garbero, A., Muttarak, R. Impacts of the 2010 droughts and floods on community welfare in rural Thailand: differential effects of village educational attainment. Ecol. Soc 2013, 18(4), 27, DOI: 10.5751/ES-05871-180427.

13. Moll, I. School was far away: the formal perceptions, classifications and syllogistic reasoning of Kokwane Ndlovu. Perspect. Educ. 1994, 15(2), 189-217.

14. Ishikawa, M., Ryan, D. Schooling, basic skills and economic outcomes. Econ. Educ. Rev. 2002, 21(3), 231-243, DOI: 10.1016/S0272-7757(01)00005-X.

15. Schnell-Anzola, B., Rowe, M.L., LeVine R. A. Literacy as a pathway between schooling and healthrelated communication skills: a study of Venezuelan mothers. Int. J. Educ. Dev. 2005, 25(1), 19-37. DOI: 10.1016/j.ijedudev.2004.05.002.

16. Ainuddin, S., Kumar Routray, J., Ainuddin, S. People's risk perception in earthquake prone Quetta city of Baluchistan. Int. J. Disast. Risk Re. 2014, 7, 165-175, DOI: 10.1016/j.ijdrr.2013.10.006.

17. Paul, B. K., Bhuiyan, R. H. Urban earthquake hazard: perceived seismic risk and preparedness in Dhaka City, Bangladesh. Disasters 2010, 34(2), 337-359, DOI: 10.1111/j.1467-7717.2009.01132.x.

18. Cotten, S. R., Gupta, S.S. Characteristics of online and offline health information seekers and factors that discriminate between them. Soc. Sci. Med. 2004, 59(9), 1795-1806, DOI: 10.1016/j.socscimed.2004.02.020. 
19. Wen, L.M., Rissel, C., Baur, L.A., Lee, E., Simpson, J.M. Who is NOT likely to access the Internet for health information? Findings from first-time mothers in southwest Sydney, Australia. Int. J. Med. Inform. 2011, 80(6), 406-411, DOI: 10.1016/j.ijmedinf.2011.03.001.

20. Neuenschwander, L.M., Abbott, A., Mobley, A.R. Assessment of low-income adults' access to technology: implications for nutrition education. J. Nutr. Educ. Behav. 2012, 44(1), 60-65, DOI: 10.1016/j.jneb.2011.01.004.

21. Patt, A.G., Ogallo, L., Hellmuth, M. Sustainability - Learning from 10 years of climate outlook forums in Africa. Science 2007, 318, 49-50, DOI: 10.1126/science.1147909.

22. Rodriguez, H., Diaz, W., Santos, J. M., Aguirre, B.E. Communicating risk and uncertainty: science, technology, and disasters at the crossroads. In Handbook of Disaster Research; Rodriguez, H., Quarantelli, E.L, Dynes, R., Eds.; Springer: New York, USA, 2007; pp. 476-488.

23. Moser, S.C., Ekstrom, J.A. A framework to diagnose barriers to climate change adaptation. In Proceedings of the National Academy of Sciences of the United States of America, 2010, 107, 22026-22031, DOI: 10.1073/pnas.1007887107.

24. Mileti, D.S., Sorensen, J.H. Communication of emergency public warnings: a social science perspective and state-of-the-art assessment. Federal Emergency Management Agency (No. Report ORNL-6609), Oak Ridge, TN, 1990.

25. Antronico, L., Coscarelli, R., De Pascale, F., Muto, F. Geo-hydrological risk perception: A case study in Calabria (Southern Italy). Int. J. Disast. Risk Re. 2017, 25, 301-311, DOI: 10.1016/j.ijdrr.2017.09.022.

26. Antronico, L., Borrelli, L., Coscarelli, R. Recent damaging events on alluvial fans along a stretch of the Tyrrhenian coast of Calabria (southern Italy). B. Eng. Geol. Environ. 2017, 76(4), 1399-1416, DOI: 10.1007/s10064-016-0922-2.

27. De Pascale, F., Bernardo, M., Muto, F. Geoethics and seismic risk perception: the case of the Pollino area, Calabria, southern Italy and comparison with communities of the past. In Geoethics: the Role and Responsibility of Geoscientists; Peppoloni, S., Di Capua, G., Eds.; Geological Society: London, Great Britain, 2015; Special Publications, 419, pp. 87-102.

28. De Pascale, F., Bernardo, M., Muto, F., Ruffolo, A., Dattilo, V. Geoethics, Neogeography and Risk Perception: Myth, Natural and Human Factors in Archaic and Postmodern Society. In Earthquakes and their impact on society; D'Amico S., Ed.; Springer Natural Hazards, 2016, pp. 665-692.

29. Tecco, N. Educazione geografica, resilienza e catastrofi naturali. In Educare al territorio, educare il territorio; Giorda, C., Puttilli, M., Eds. Geografia per la formazione, Carocci, Roma, 2011, pp. 308-320. 